\title{
Quantifying the attractiveness of garden flowers for pollinators
}

\author{
Rosi Rollings ${ }^{1} \cdot$ Dave Goulson ${ }^{2}$ (D)
}

Received: 16 July 2019 / Accepted: 6 September 2019 / Published online: 14 September 2019

(c) The Author(s) 2019

\begin{abstract}
There is great interest in planting urban areas to benefit pollinating insects, with the potential that urban areas and gardens could act as an extensive network of pollinator-friendly habitats. However, there are a great many different plant cultivars available to the gardener, and a paucity of evidence-based advice as to which plants are truly most attractive to flowervisiting insects. Here, we report insect visitation to metre square plots of 111 different ornamental plant cultivars at a site in central UK. Data were collected over 5 years, and comprise over 9000 insect observations, which were identified to species (for honeybees and bumblebees) or as 'solitary bees', Syrphidae, Lepidoptera and 'others'. Unlike some previous studies, we found no difference in numbers of insects attracted to native or non-native species, or according to whether plants were annuals, biennials or perennials, but we did find that native plants attracted a significantly higher diversity of flower-visiting insects. Overall, the most-visited plants were Calamintha nepeta, Helenium autumnale and Geranium rozanne. However, patterns of visitation were quite different for every insect taxa examined. For example, different species of short-tongued bumblebees showed little overlap in their most-preferred plant cultivars. Interestingly, very similar plant cultivars often attracted different insect communities; for example, $72 \%$ of visitors to Aster novi belgii were honeybees or bumblebees, while the related Anthemis tinctoria, which also has daisy-like flowers, did not attract a single honeybee or bumblebee but was popular with solitary bees, hoverflies, and 'other' pollinators. Some plant cultivars such as Eryngium planum and Myosotis arvensis were attractive to a broad range of insects, while others attracted only a few species but sometimes in large numbers, such as Veronicastrum virginicum and Helenium autumnale which were both visited predominantly by honey bees. It is clear that we do not yet fully understand what factors drive insect flower preferences. Recommendations are made as to which flower cultivars could be combined to provide forage for a diversity of pollinator groups over the season from early spring to autumn, though it must be born in mind that some plants are likely to perform differently when grown in different environmental conditions.
\end{abstract}

Keywords Pollinator $\cdot$ Flower $\cdot$ Urban areas $\cdot$ Wildlife gardening $\cdot$ Insects

\section{Introduction}

Promoting wildlife friendly gardening has become a common strategy intended to help mitigate declines in wildlife, particularly with regard to pollinators such as bees (e.g. Goddard et al. 2010; Mader et al. 2011). There is mounting evidence that pollinators are in decline at a global scale (Goulson and Rotheray 2015; Rhodes 2018), and conservation

Dave Goulson

D.Goulson@sussex.ac.uk

1 Rosybee Plants for Bees, Steventon Rd, East Hanney OX12 0HS, UK

2 School of Life Sciences, University of Sussex, Brighton BN1 9RH, UK organisations see an opportunity to use urban green spaces (gardens, parks, green roofs, allotments, churchyards and so on) to create a network of wildlife habitat bees (e.g. Goulson et al. 2011; Hall et al. 2016; Levé et al. 2019). There is clear evidence that urban areas can support a considerable diversity of pollinators, often at higher abundance than in nearby farmland (Goulson 2010; Bates et al. 2011; Samnegard et al. 2011), but it seems likely that there is scope for improvement.

The most obvious step that gardeners might take to encourage pollinators is to plant flowers for them, but which ones should they plant? Ornamental plants are enormously variable in their attractiveness to pollinators (e.g. Garbuzov and Ratnieks 2014b), and many cultivars that have been bred by artificial selection have become much less attractive to 
insect visitors; for example some double varieties have extra sets of petals instead of anthers (Corbet et al. 2001). Many lists have been published of the ones recommended for pollinators, for example on the websites of organisations such as the Royal Horticultural Society, the Bumblebee Conservation Trust, and the Xerces Society, or in the many books about wildlife gardening. However, these lists appear to be largely based on anecdote or casual observation rather than scientific evidence (Garbuzov et al. 2017). Garbuzov and Ratnieks (2014a) compared 15 such lists, and conclude that they are inconsistent, often contradictory, often omit many good plants, and sometimes contain poor recommendations. Rather few attempts have been made to rigorously evaluate which garden plants are most attractive, using a standardise technique (exceptions include Garbuzov and Ratnieks 2014b, 2015; Salisbury et al. 2015; Garbuzov et al. 2015a, b). Those that have, often find considerable variation within members of a particular Genus; for example, different Lavandula cultivars vary tenfold in the numbers of bees they attract (Garbuzov and Ratnieks 2014b), so providing generic advice such as "lavenders are good for bees" is not particularly helpful.

Clearly there is a need for more objective trials to determine which cultivars of ornamental plant are most attractive to pollinators. Here, we present data on the attractiveness of 111 cultivars of garden plant to pollinators. Plants were grown under standardised conditions in the UK over a 5 year period (2014-2018), and visiting insects were identified to species for honeybees and bumblebees, or pooled into the categories: solitary bees; Lepidoptera; hoverflies; other pollinators. There are many thousands of cultivars of plants available to gardeners, so we included only those that we already had reason to believe were attractive to pollinators, based on personal observations or inclusion in one of the lists mentioned above. Although much more data are needed under different conditions and spanning more cultivars, nonetheless our data should help gardeners make more informed decisions when attempting to provide flowers for insects.

\section{Methods}

The study was carried out on a 2.5 ha plant nursery in South Oxfordshire, UK $\left(51.636^{\circ} \mathrm{N},-1.389^{\circ} \mathrm{E}\right)$, situated on the edge of a village and largely surrounded by arable fields (predominantly wheat and oilseed rape with occasional barley and field beans). Four honey bee hives were situated on site throughout the study period. The soil consists of heavy clay over gravel.

We tested 111 plant cultivars in total, including 89 perennials, 6 biennials and 16 annuals. Twenty-five of the plants were UK natives, the remaining 86 being non-native. The study ran from 2014 to 2018 , starting with 45 plant cultivars, with more added each year and seven removed after the first year as they attracted very few insects. Data were obtained from most plant cultivars from at least 2 years, with 63 plant cultivars having data for three or more years (Table 1).

Each plant cultivar was allocated to a $1 \times 1 \mathrm{~m}^{2}$ plot in an experimental bed, and sufficient individuals planted to fill the bed once mature. Plots were immediately adjacent to one another. Management consisted only of weeding, removal of dead flower heads in the winter, and occasional watering during very dry weather; all plants were treated the same. Insect observations began once the plant began flowering, and were made every week for the duration of flowering, beginning in week 9 ( end of February/beginning of March) and continuing to week 43 (mid October), weather permitting. Observations were made between 1100 and 1600, on days when it was not raining or excessively windy (the latter corresponding to point 6 on the Beaufort Scale, when large branches on trees begin to sway). All flowering plant species were observed on any day that recording took place. Insect visitor observations used the "snapshot" method of Garbuzov and Ratnieks (2014b), in which a near-instantaneous count is made of the insects visiting each plot. If more than eight insects were observed, a second count was made approximately $5 \mathrm{~min}$ later, and the mean used in analyses. Honey bees and the common seven bumblebee species $(B$. terrestris, B. lucorum, B. pratorum, B. pascuorum, B. hypnorum, $B$. hortorum, $B$. lapidarius) were identified to species in the field. The sister species Bombus terrestris and Bombus lucorum were distinguished as well as possible in the field but it is likely that some workers may have been misclassified as the two species are very similar. If the identity of a bumblebee was in doubt, photographs were taken for further examination. The remaining insects were grouped as either other bumblebees, 'solitary' bees, Lepidoptera, Syrphidae and other insects. Very small insects, such as thrips and pollen beetles, were not recorded.

If a plant cultivar did not fill the plot, or spilled out of the plot, the area of the plant was estimated and the number of insect visitors observed was adjusted to give an estimate per square meter. It has previously been shown that the number of insect visitors per unit area is not affected by patch size, at least within the range of patch sizes typically found within gardens (Garbuzov et al. 2015a).

To compare flower cultivars, numbers of insect visitors observed each week were summed for each year. By this approach, a plant with a long flowering period of 10 weeks, on which only one insect was observed each week, would score 10. A plant that flowered for just 1 week but had ten insects on it would score the same. Where data were available for multiple years, a mean was calculated across years.

Simply calculating the mean number of visits to each plant cultivar inevitably means that the plant cultivars that 


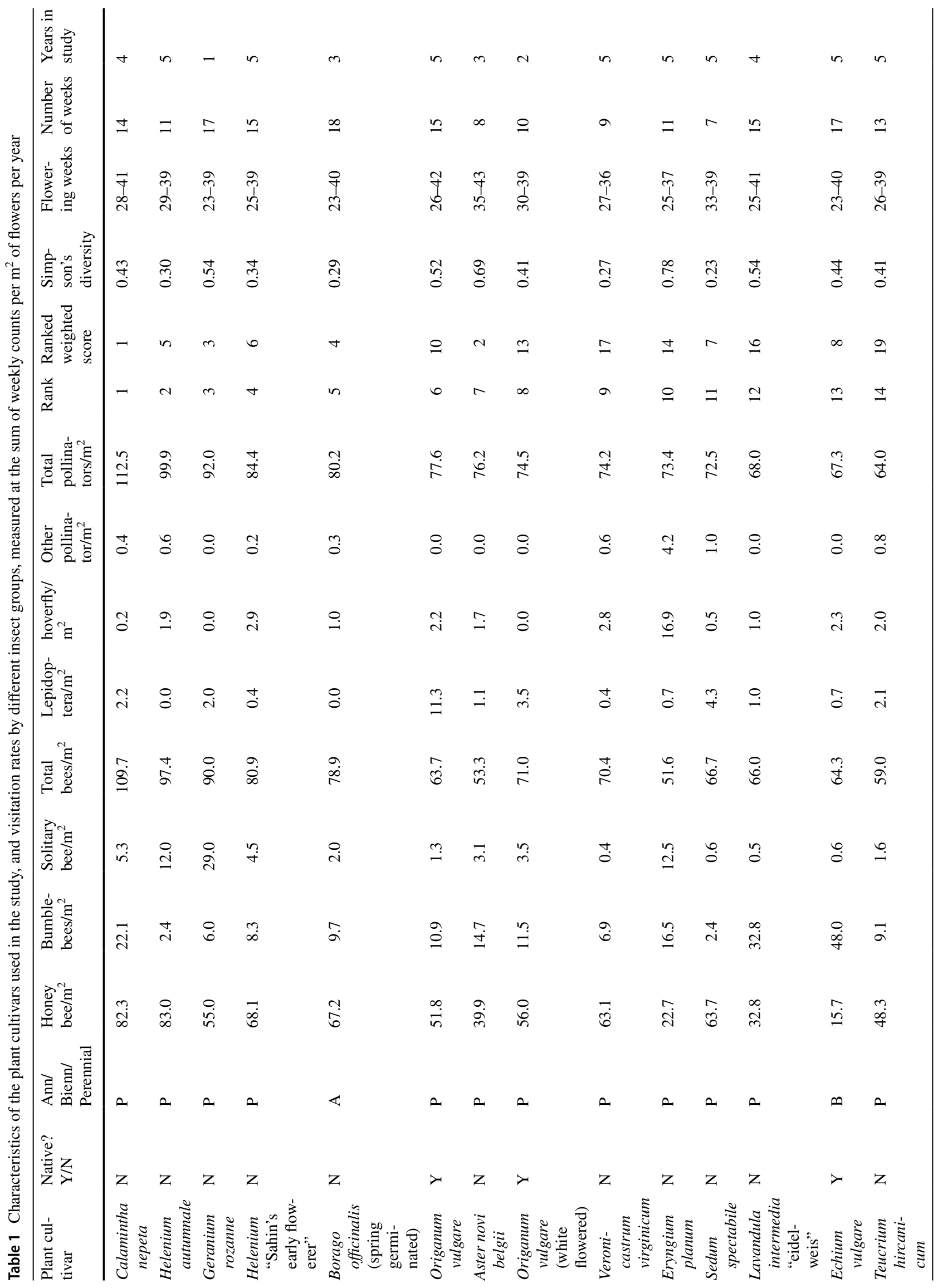




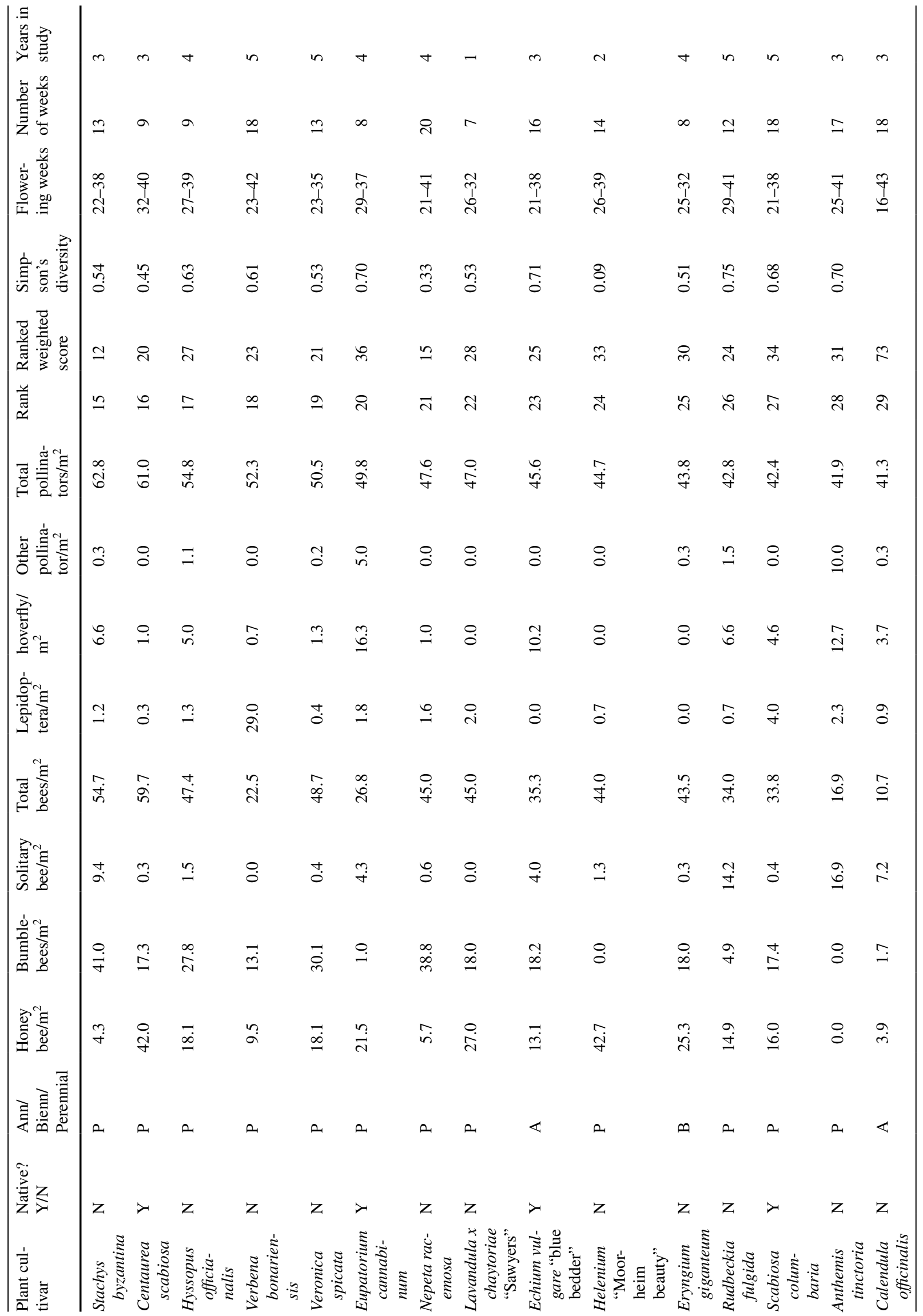




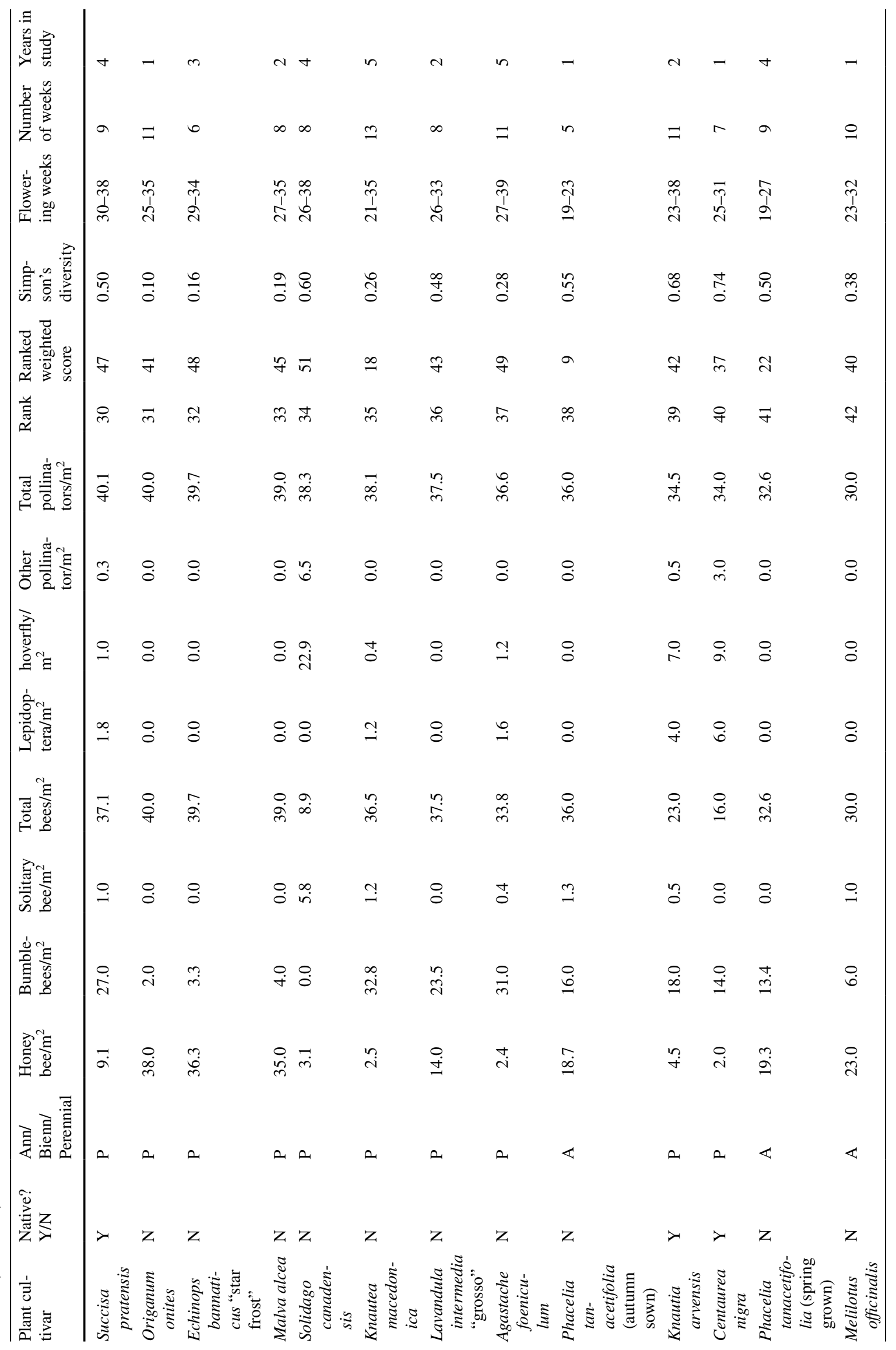




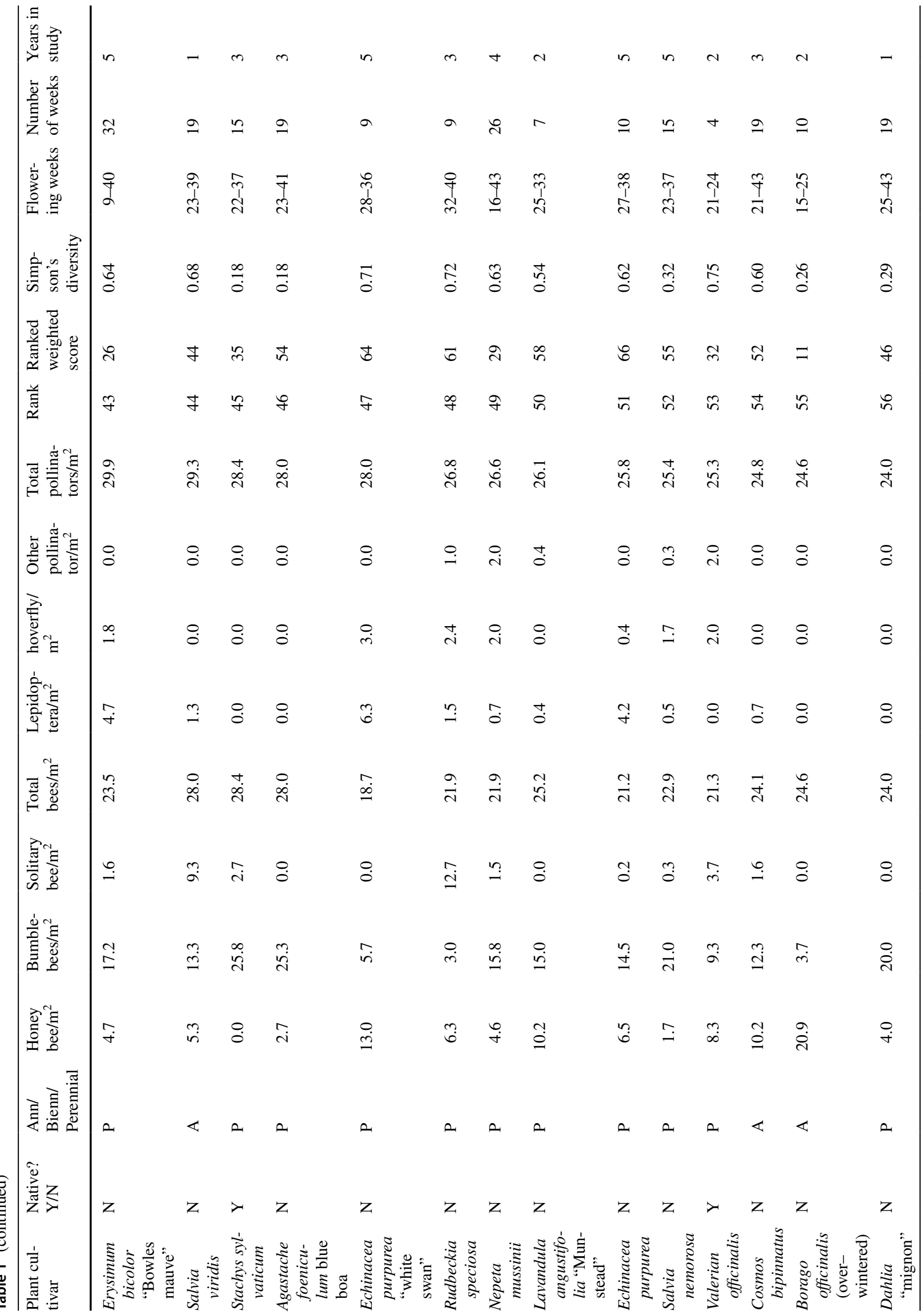




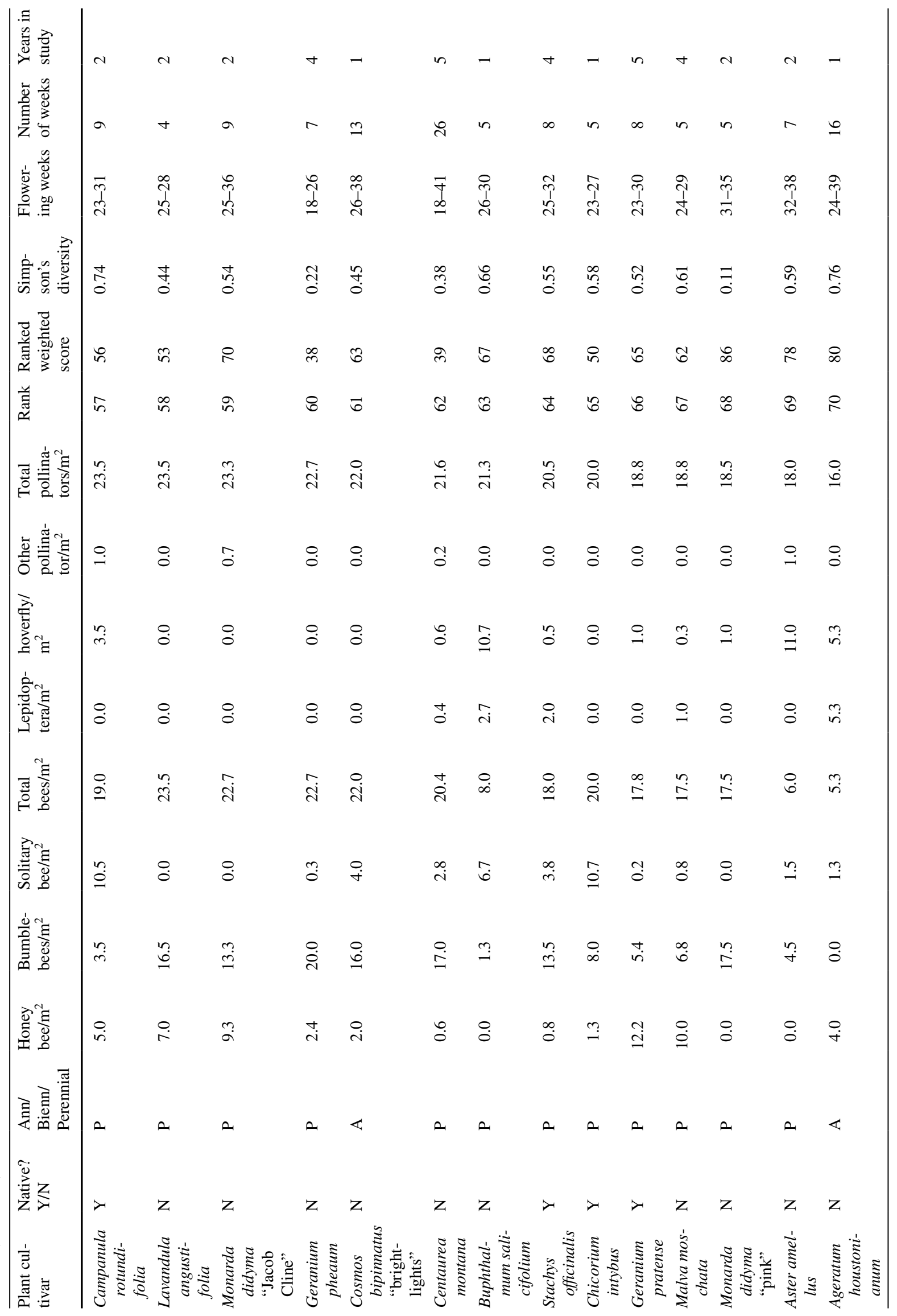


810

Journal of Insect Conservation (2019) 23:803-817

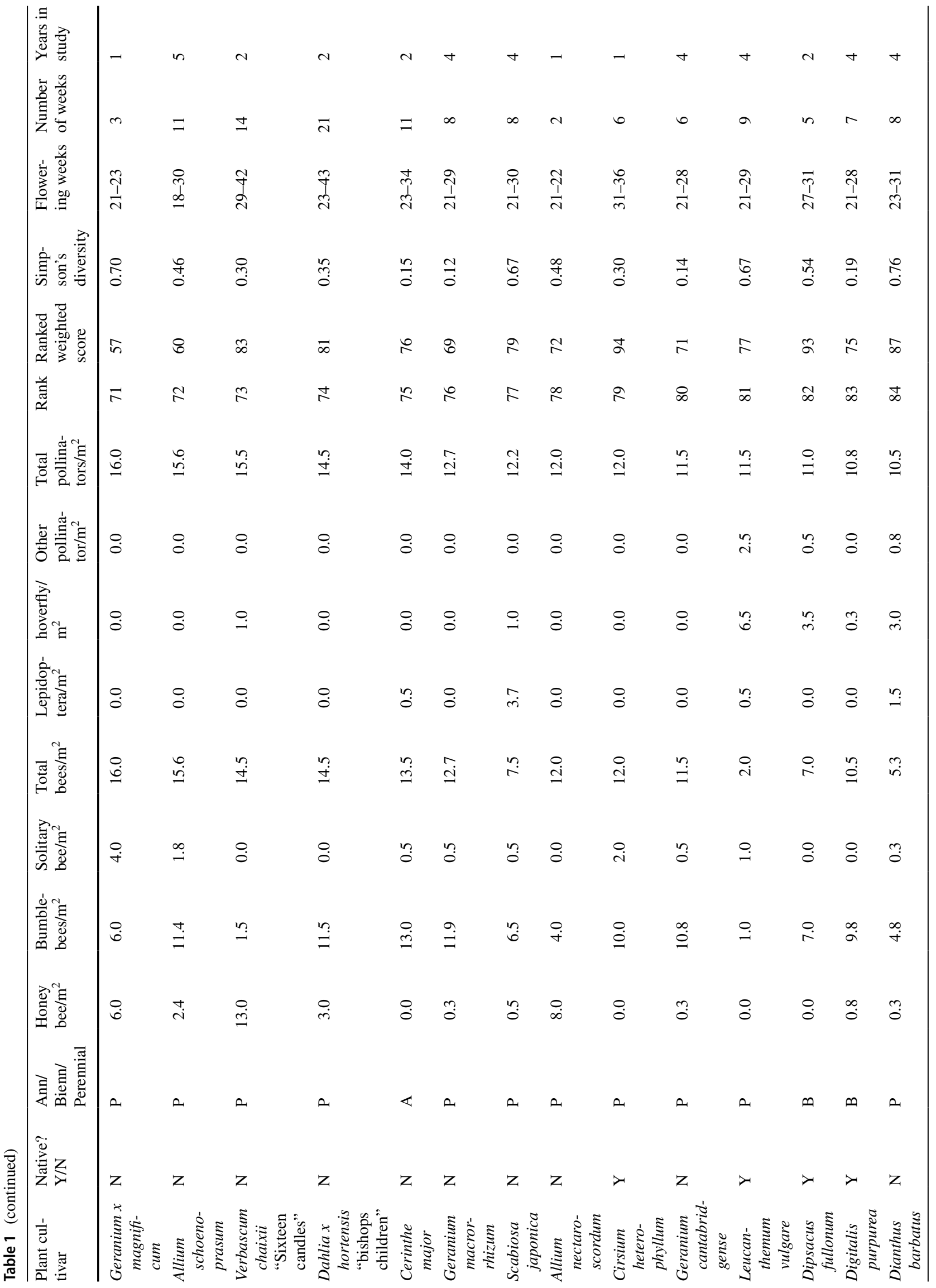

Springer 


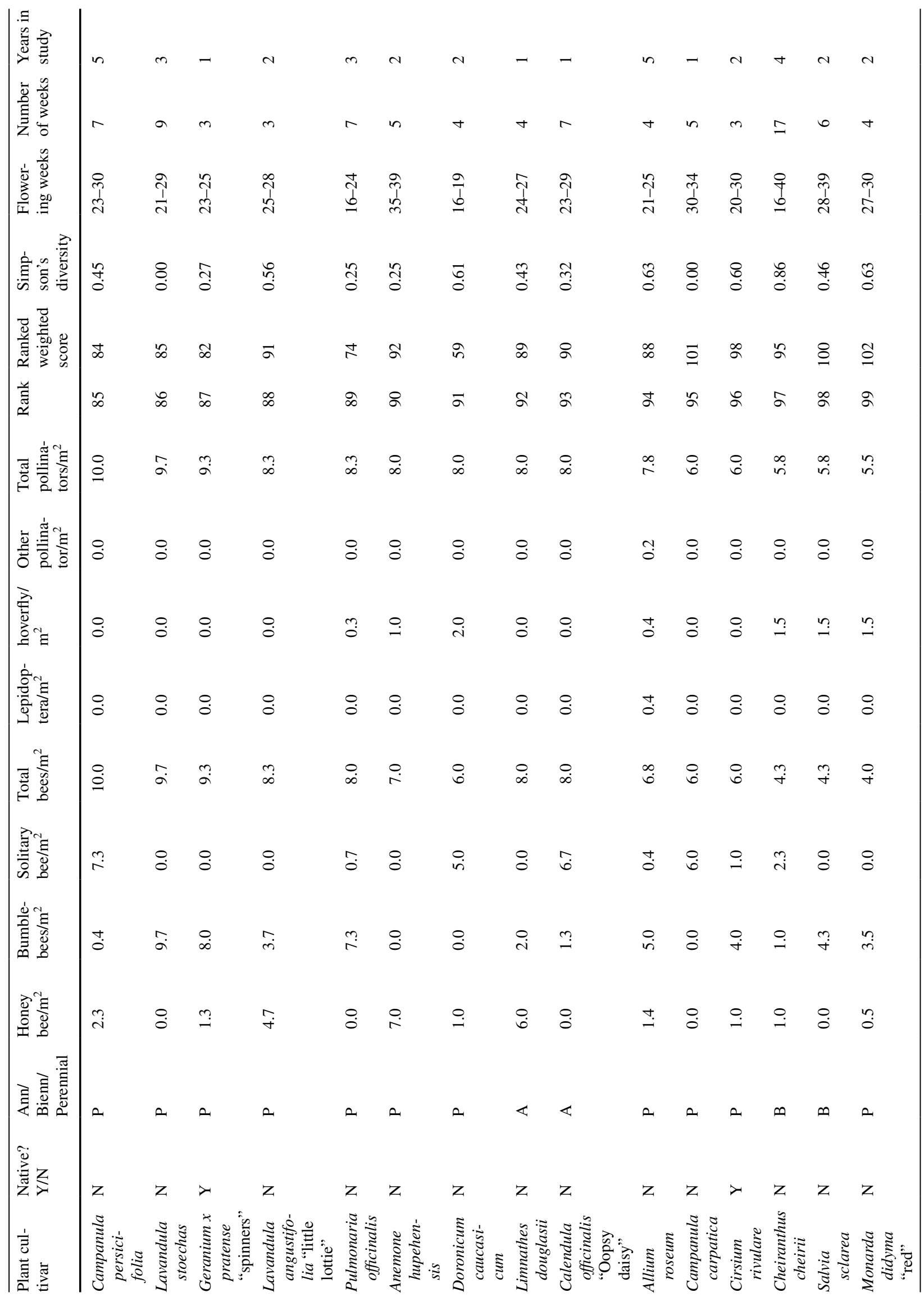




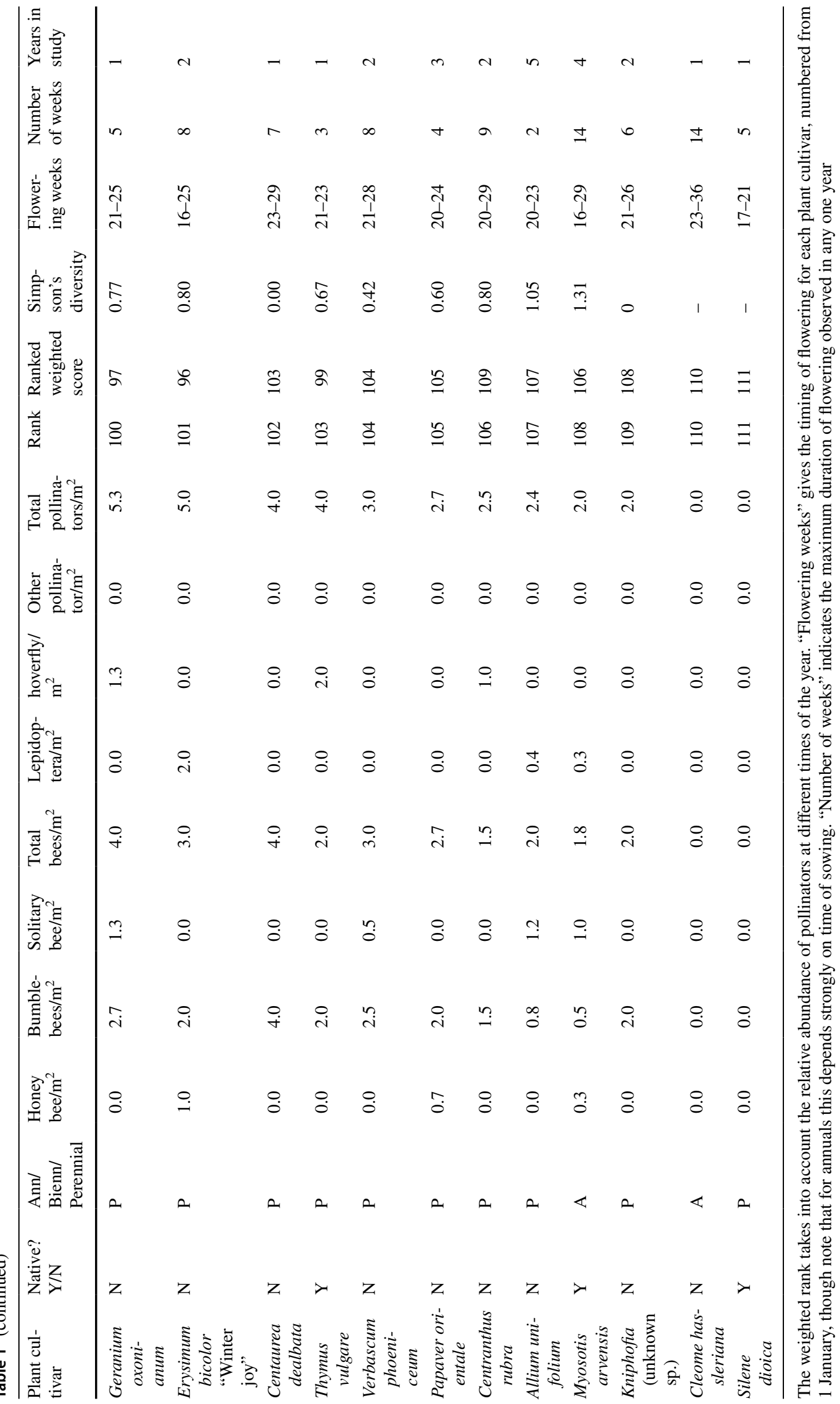


come out highest in the ranking of visitor numbers tend to be those that flower in summer, when insect numbers are highest. To calculate an index of attractiveness to flower-visiting insects for each plant that takes into account the seasonal patterns of abundance of insect flower visitors, we divided the number of visitors to each plant cultivar in each week by the mean number of insect visitors observed across all plant cultivars in that same week. This was then used to calculate a weighted rank attractiveness to insects.

A Simpson's diversity index for insect visitation was calculated for each plant cultivar, using the mean numbers of visits per year by each of the insect groups (honey bees, bumblebees, solitary bees, hoverflies, lepidopterans, others).

To evaluate whether origin of the plant (native or nonnative) or its longevity (annual, biennial or perennial) was a predictor of attractiveness, we constructed generalized linear models with origin and longevity as explanatory variables, using a single mean insects $/ \mathrm{m}^{2} /$ year for each plant cultivar (since the same patches were observed on multiple years we could not use yearly data). Separate models were constructed for numbers of visits by honey bees, bumblebees, solitary bees, Lepidoptera, hoverflies, all insect visitors pooled, and for Simpson's diversity.

\section{Results}

Overall, 4825 honey bees, 3388 bumblebees, 702 solitary bees, 624 hoverflies, 435 lepidopterans and 161 other insects were observed visiting the flowers in the experimental patches over the 5 years. Although the plants included in the study were pre-selected on the basis of recommendations that they were attractive to flower-visiting insects, there was enormous variation in the numbers of insects they attracted (Table 1). Overall, Calamintha nepeta attracted the most insects, with an average yearly sum of 112 insects/ $\mathrm{m}^{2}$, most of them being honey bees. Helenium autumnale, Echium vulgare, Geranium rozanne, Verbena bonariensis and Solidago canadensis were the most attractive plants for honeybees, bumblebees, solitary bees, Lepidoptera and hoverflies, respectively. At the other end of the spectrum, Silene dioica and Cleome hassleriana attracted no insects while being observed.

Focussing in on the individual bumblebee species, $B$. pascuorum was most abundant overall (comprising $36.1 \%$ of all bumblebees), followed by $B$. terrestris (19.7\%), $B$. pratorum $(14.3 \%)$, B. lucorum $(9.5 \%)$, B. hortorum $(7.6 \%)$, B. lapidarius (7.3\%), and B. hypnorum (2.3\%). There was little overlap between the most-visited plants for each species (Table 2). Only one plant cultivar, Knautia macedonica, occurred in more than two lists of the top six plants visited by each bumblebee species. Most overlap was seen between the sister species B. pratorum and B. hypnorum,

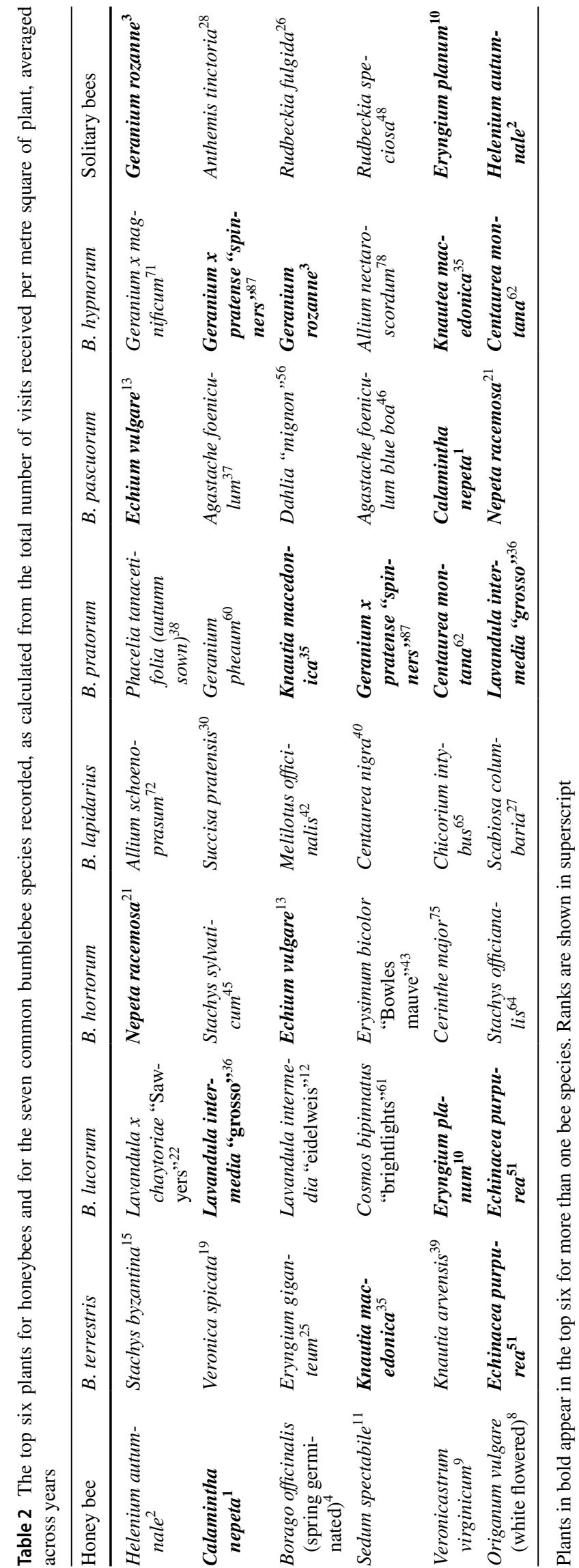


which shared three of their top six most-visited plants, and both of which showed a strong preference for Geranium of various types. B. lapidarius did not share any of its top six most visited plants with any other bumblebee bee species.

The timing and duration of flowering were of course highly variable between plant cultivars (Table 1). Notable for the long duration of flowering were Erysimum bicolor "Bowles Mauve" (32 weeks), Nepeta mussini (26 weeks) and Centaurea montana (26 weeks), all of them flowering for 6 months or more (and note that we did not monitor in late autumn and winter).

As one might expect, strong seasonal patterns were evident in the numbers of insect visitors to flowers (Fig. 1). The first insects were recorded in week 9 ( late February/early March), and increased approximately linearly to a peak in week 32 (early August). Thereafter numbers declined into autumn, with the exception of a smaller peak right at the end of the season in mid October. However, this latter point is based on only six individual flower counts and so could be a result of sampling error. The seasonal pattern was broadly similar for all of the different insect groups (Fig. 1).

Taking into account the relative abundance of insect visitors in each week of the year to create a weighted rank of the attractiveness of each plant cultivar did not dramatically change the rankings for most cultivars, with $C$. nepeta remaining the top-ranked plant. Some spring-flowering plants rose considerably, notably Doronicum caucasicum, autumn-sown Borago officinalis, and Centaurea montana. As one might expect, some summer-flowering plants fell in their rankings, notably Echinacea purpurea.

The large majority of plant cultivars included in this study attracted a diversity of different insects (diversity indices in Table 1). For example, of the top 30 plants when ranked by overall insect visitation, 21 of them received visits from at least five of the six insect groups (honey bees, bumblebees, solitary bees, hoverflies, Lepidoptera, others). The plants with lowest diversity of visitors tended to be ones on which honey bees dominated, such as Helenium autumnale, Sedum spectabile, Origanum onites and Veronicastrum virginicum. High ranking plants which also attracted a high diversity of flower-visiting insects included Eryngium planum (Simpson's D $=0.78$ ), Rudbeckia fulgida (Simpson's D = 0.75) and Aster novi belgii (Simpson's D $=0.69$ ), which were all visited by all six of the insect groups.

The total number of flower-visiting insects on plants was not significantly different between native and non-native

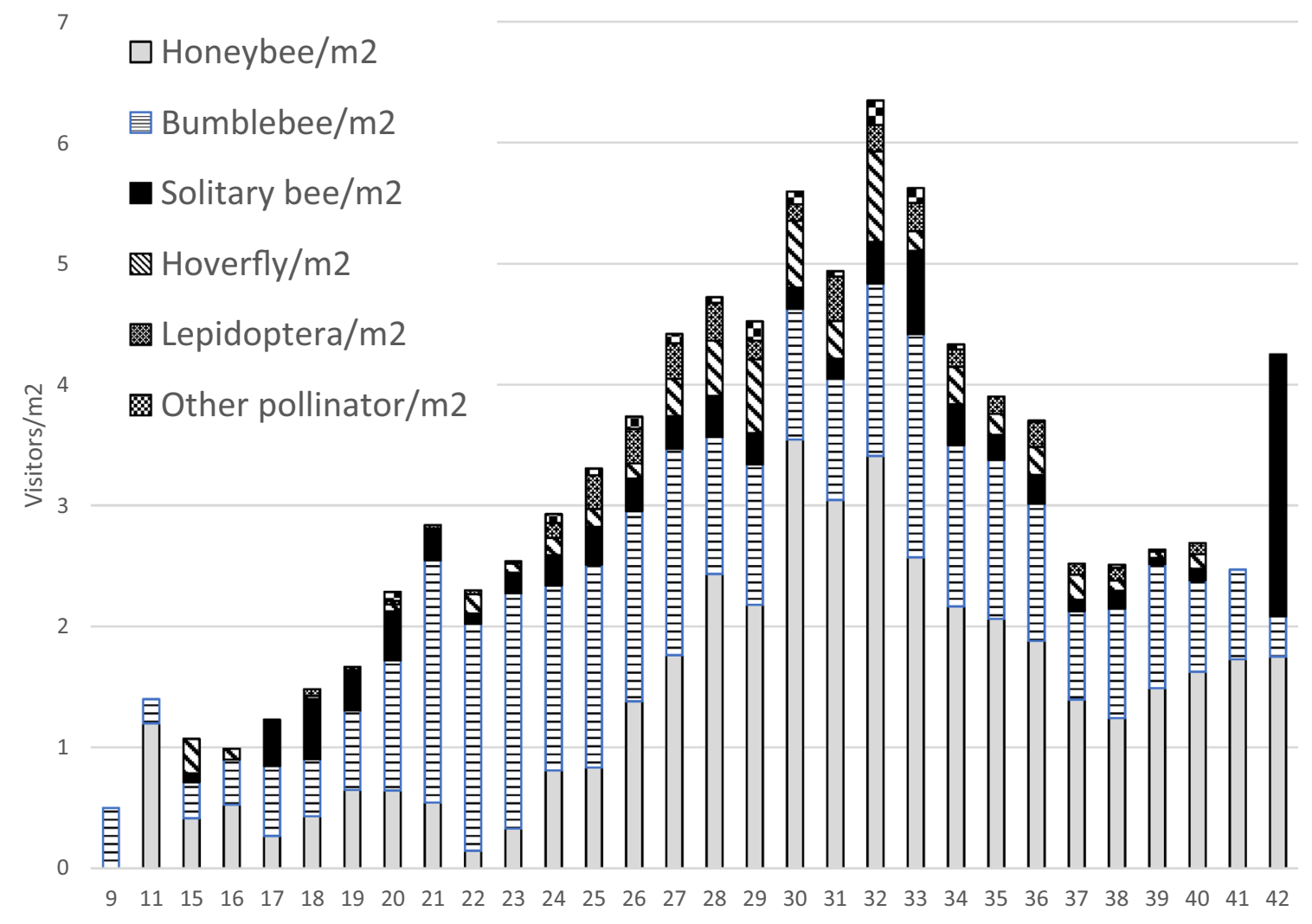

Week

Fig. 1 Number of insect visits $/ \mathrm{m}^{2}$ of flowers in each week of the year, averaged across all flower cultivars 
plants (mean \pm SE: $27.1 \pm 7.5$ and $25.5 \pm 5.2$, respectively, $\chi^{2}=0.28$, d.f. $=1, p=0.60$ ), or between annuals, biennials and perennials (mean \pm SE: $24.8 \pm 6.4,24.1 \pm 9.9$ and $30.2 \pm 2.9$, respectively, $\chi^{2}=0.95$, d.f. $=2, p=0.62$ ). Similarly, when numbers of honey bees, bumblebees, solitary bees, Lepidoptera or hoverflies were analysed, no differences were found between native and non-native plants or according to plant longevity (data not shown, none are close to statistical significance). The diversity of insect visitors (Simpson's D) did not differ between annuals, biennials or perennials but insect diversity was significantly higher on native plants compared to non-natives (mean $\pm \mathrm{SE}$ : $0.584 \pm 0.054$ and $0.467 \pm 0.041$ for natives and non-natives, respectively, $\chi^{2}=4.79$, d.f. $=1, p=0.029$ ).

\section{Discussion}

Our results are broadly in accord with published lists as to which plants are best at attracting flower-visiting insects, but with some notable anomalies. In particular, the highest ranking plant in our study, C. nepeta, is not in the top 38 most frequently included Genera in the fifteen lists of recommended plants compiled by Garbuzov and Ratnieks (2014a). It is a relatively inconspicuous plant with small pale purple flowers, and as a result is not widely grown and may thus have escaped the attention of those making such lists. Borago officinalis was included in less than half of these 15 lists, but was the fifth most attractive plant in our study, and was also found to be highly attractive in a comparative field trial performed by Garbuzov and Ratnieks (2014b). Similarly Teucrium hircanicum and Echium vulgare both seem to have been largely overlooked in these lists (three and four of 15 lists, respectively) but seem to be excellent plants for insects (ranked 14th and 13th, respectively). Conversely, Limnanthes douglasii is included in 10 of the 15 lists examined by Garbuzov and Ratnieks, but was ranked very low (89th) in our study, and Dianthus barbatus was on 13 of the 15 lists but also scored poorly in our study (85th). As Garbuzov and Ratnieks (2014a) note, some lists may be created by copying others, so that errors come to be repeated over time.

Of course no evidence of this sort is definitive, and our study is based on repeated observation of single plots per cultivar, meaning that we are unable to assess whether there are neighbour effects between plant cultivars. Ideally, one would have randomly distributed replicate patches, and multiple experimental sites situated on a range of soil types and microclimates, since this will undoubtedly have an effect on the performance of the plants. For example neither Monarda didyma nor Agastache foeniculum appeared to thrive on the clay soil of the experimental site, with plants often dying in the winter. That may explain why these two plants, which other studies have found to be very attractive to insects (e.g. Garbuzov and Ratnieks 2014b), did not perform particularly well. In optimal conditions a plant will produce more flowers and may also provide more floral rewards per flower. Additionally, we only recorded once per day and did not attempt to study daily variation in attractiveness of plants, yet it is known that some plants tend to release their rewards at particular times. Clearly much more work of this kind is needed to build a more complete picture as to which plants are most attractive, and how this varies according to site characteristics.

Most plant cultivars included in this study appeared to be quite generalized with regard to the range of insects that visited them (Table 1). This is to be expected, as generalization is common in plant-pollinator mutualisms, with rather few plants strongly specialized towards pollination by a small number of taxa (Waser et al. 1996). Nonetheless it is interesting that some plants with very similar floral structures attracted different pollinator communities. For example both Helenium cultivars included in the study attracted mainly honeybees ( 83 and $96 \%$ of all visits), while other Asteraceae with a similar flower structure suitable for insects with short tongued attracted far lower proportions of honey bees (e.g. Aster novi belgii 52\%; Rudbeckia fulgida 35\%, Echinacea purpurea 23\%). Most strikingly, Anthemis tinctoria, another Asteraceae with a typical daisy-like flower, did not attract a single honeybee or bumblebee but was popular with solitary bees, hoverflies, and 'other' flower-visiting insects.

Even within bumblebees, which in most respects share a broadly similar morphology, markedly different floral preferences were evident (Table 2). Bumblebees do exhibit considerable variation in tongue length which is known to influence floral choices (Goulson et al. 2008; Goulson 2010; Plowright and Plowright 2012). Of the species present in our study, $B$. hortorum has a much longer tongue than the others, with $B$. pascuorum having a tongue of intermediate length and all the rest having short tongues, although still slightly longer than that of the honey bee (tongue lengths are reported in Goulson et al. 2008). The two longer-tongued bumblebees shared two of their six most-visited plants (Nepeta racemosa and Echium vulgare), but both of these plants were also frequently visited by many of the shorttongued species too, including honey bees. Notably, marked differences were observed in the most-preferred flowers visited by bees with very similar length short tongues. For example B. lapidarius shared none of its six most-visited plants with any other bumblebee species or with honeybees. Even the closely-related species B. terrestris and B. lucorum, which are indistinguishable in terms of tongue length, shared only one plant cultivar amongst their most-visited top six. Perhaps the insects are responding differentially to subtle differences in the quality or quantity of floral rewards. They are likely to also be influenced by competitive interactions 
with other flower visiting insects (e.g. Garbuzov and Ratnieks 2013). There is much that we still do not understand about the foraging choices of bumblebees and other flowervisiting insects.

The geographic origins of plants (native or non-native) did not appear to influence the number of insects that visited them, but native plants attracted a higher diversity of flowervisiting insects. Salisbury et al. (2015) found that insect visitors preferred native or near-native plants (the latter defined as relatives of native plants, and naturally occurring in the Northern Hemisphere) to exotic ones (cultivars from the Southern Hemisphere). Almost all of the plants included in our study would have fallen into the native or near-native categories. Our plant cultivars were chosen because they were claimed to be attractive to insect visitors in the UK, so we did not have any plants with specialist pollinators that are not present in the UK, such as bird-pollinated plants from South America (with the sole exception of Cleome hassleriana which received no visits). It is perhaps not surprising that UK flower-visiting insects readily visit nearnative plants (which were mostly from Europe and North America), plants that are adapted to pollination by broadly similar fauna. For example, the bumblebees of North America are morphologically very similar to those of Europe, so it is not surprising that European bumblebees will readily visit American plants such as Echinacea, Solidago and Monarda. Nonetheless it is interesting that native plants attracted a higher diversity of different insect types, perhaps suggesting a greater degree of co-adaptation.

In contrast to the citizen science survey of Fussell and Corbet (1992), who found that UK bumblebees preferred perennial to annual plants, we found no difference in insect visits to annuals, biennials or perennials. Fussel and Corbet infer this from the observation that, of the 37 plant species that were 'preferred' by bumblebees, only two were annuals. Inspection of our data reveal that only three of the 37 highest-ranking plants in our study were annuals (Borago officinalis, Echium vulgare "blue bedder" and Phacelia tanacetofilia) so in reality there is no contradiction between the findings of the two studies.

The results presented here should prove useful for anyone intending to encourage flower-visiting insects in a garden or urban greenspace in Britain or other countries with similar climate (e.g. much of NW Europe, parts of North America), but caution is needed. It must be born in mind that plants will perform differently in different soils or climatic conditions. Without spatial replication (multiple plots per cultivar) we cannot be certain that some of the differences between plant cultivars were not due to their location within the experimental site. However, it would be enormously challenging to conduct a fully-replicated experiment with so many cultivars, and funding for this sort of study is unlikely to be readily available, so it is unlikely that any such study will be performed in the near future. We suggest that, however imperfect, having some data is better than none.

It should also be noted that there are undoubtedly many other excellent plants for pollinators that we did not include in these trials. Nonetheless, below we make some tentative planting suggestions for those who wish to attract flower-visiting insects and are attempting to choose from among the many cultivars that are commercially available.

To cater for the full range of flower-visiting insects one ideally needs to provide plants suitable for different insect types and ones that span the flight season from late winter through to mid-autumn. For example, for maximum attraction of insects one might include any of Calamintha nepeta, Geranium rozanne, Helenium autumnale, Origanum vulgare and Borago officinalis. To increase diversity of flower-visiting insects one might include natives such as Myosotis arvensis, Valerian officinalis and Centaurea nigra alongside non-natives such as Rudbeckia fulgida, Eryngium planum and Aster novi belgii. Echium vulgare and Nepeta racemosa would help to cater for long-tongued bumblebees, and Anthemis tinctoria for solitary bees, while Verbena bonariensis and Solidago canadensis would provide resources for Lepidoptera and hoverflies, respectively. Flowers are often in short supply in early spring when queen bumblebees and a number of solitary bees emerge, and Pulmonaria officinalis, Centaurea montana, Nepeta mussini and autumn-sown Borago officinalis are all useful at this time. For a very long flowering duration including flowers in early spring, combined with being visited by a broad range of flower-visiting insects, Erysimum bicolor "Bowles Mauve" is very versatile.

In future, it would be valuable to test these and other plant cultivars at other sites with different environmental conditions, so that recommendations tailored by region and soil-type can be provided. It would also be useful to identify more of the insect visitors to species, as groups such as 'solitary bees' and hoverflies contain diverse species which are very likely to have different floral preferences that we did not capture.

\section{Compliance with ethical standards}

Conflict of interest We have no conflicts of interest.

Research involving human and animal rights Wild animals were observed but not interfered with in any way during this work. There were no human participants.

Open Access This article is distributed under the terms of the Creative Commons Attribution 4.0 International License (http://creativecommons.org/licenses/by/4.0/), which permits unrestricted use, distribution, and reproduction in any medium, provided you give appropriate credit to the original author(s) and the source, provide a link to the Creative Commons license, and indicate if changes were made. 


\section{References}

Bates AJ, Sadler JP, Fairbrass AJ, Falk SJ, Hale JD (2011) Changing bee and hoverfly Pollinator assemblages along an urban-rural gradient. PLoS ONE 6:e23459

Corbet SA, Bee J, Dasmahapatra K, Gale S, Gorringe E, La Ferla B, Moorhouse T, Trevail A, Vab Bergen Y, Vorontsova M (2001) Native or exotic? Double of single? Evaluating plants for pollinator-friendly gardens. Ann Bot 87:219-232

Fussell M, Corbet SA (1992) Flower usage by bumble-bees: a basis for forage plant management. J Appl Ecol 29:451-465

Garbuzov M, Ratnieks FLW (2013) Quantifying variation among garden plants in attractiveness to bees and other flower-visiting insects. Funct Ecol 28:364-374

Garbuzov M, Ratnieks FLW (2014a) Listmania: the strengths and weaknesses of lists of garden plants to help pollinators. Bioscience 64:1019-1026

Garbuzov M, Ratnieks FLW (2014b) Quantifying variation among garden plants in attractiveness to bees and other flower-visiting insects. Funct Ecol 28:364-374

Garbuzov M, Ratnieks FLW (2015) Using the British national collection of asters to compare the attractiveness of 228 varieties to flower-visiting insects. Environ Entomol 44:638-646

Garbuzov M, Madsen A, Ratnieks FLW (2015a) Patch size has no effect on insect visitation rate per unit area in garden-scale flower patches. Acta Oecol 62:53-57

Garbuzov M, Samuelson EEW, Ratnieks FLW (2015b) Survey of insect visitation of ornamental flowers in Southover Grange garden, Lewes, UK. Insect Sci 22:700-705

Garbuzov M, Alton K, Ratnieks FLW (2017) Most ornamental plants on sale in garden centres are unattractive to flower-visiting insects. PeerJ 5:e3066

Goddard MA, Dougill AJ, Benton TG (2010) Scaling up from gardens: biodiversity conservation in urban environments. TREE 25:90-98

Goulson D (2010) Bumblebees; their behaviour, ecology and conservation. Oxford University Press, Oxford

Goulson D, Lye GC, Darvill B (2008) Diet breadth, coexistence and rarity in bumblebees. Biodivers Conserv 17:3269-3288

Goulson D, Rayner P, Dawson B, Darvill B (2011) Translating research into action; bumblebee conservation as a case study. J Appl Ecol $48: 3-8$
Goulson D, Nicholls E, Botías C, Rotheray EL (2015) Combined stress from parasites, pesticides and lack of flowers drives bee declines. Science 347:1435

Hall DM, Camilo GD, Tonietto RK, Ollerton J, Ahrné K, Arduser M, Ascher JS, Baldock KCR, Fowler RE, Frankie GW, Goulson D, Gunnarsson B, Hanley ME, Jackson JI, Langellotto G, Lowenstein D, Minor ES, Philpott SM, Potts SG, Sirohi MH, Spevak EM, Stone G, Threlfall C (2016) The city as a refuge for insect pollinators. Conserv Biol 31:24-29

Levé M, Baudry E, Bessa-Gomes C (2019) Domestic gardens as favourable pollinator hábitats in impervious landscapes. Sci Total Environ 647:420-423

Mader E, Shepherd M, Vaughan M, Black S (2011) Attracting native pollinators: protecting North America's bees and butterflies. Storey Publishing, North Adams

Plowright CMS, Plowright RC (2012) The advantage of short tongues in bumblebees (Bombus) - analyses of species distributions according to flower corolla depth, and of working speeds on white clover. Can Entomol 129:51-59

Rhodes CL (2018) Pollinator decline-an ecological calamity in the making? Sci Prog 101:121-160

Salisbury A, Armitage J, Bostock H, Pery J, Tatchell M, Thompson $\mathrm{K}$ (2015) Enhancing gardens as habitats for flower-visiting aerial insects (pollinators): should we plant native or exotic species? J Appl Ecol 52:1156-1164

Samnegard U, Persson AS, Smith HG (2011) Gardens benefit bees and enhance pollination in intensively managed farmland. Biol Conserv 144:2602-2606

Waser NM, Chittka L, Price MV, Williams NM, Ollerton J (1996) Generalization in pollination systems, and why it matters. Ecology $77: 1043-1060$

Publisher's Note Springer Nature remains neutral with regard to jurisdictional claims in published maps and institutional affiliations. 